\title{
Histopathological Examination of Routine Tonsil or Adenoid Specimens in a Tertiary Care Centre of Nepal: Evaluation of Its Necessity and Cost-Benefit Rate Analysis
}

\author{
Sushna Maharjan ${ }^{1 *}$, Puja Neopane ${ }^{2}$, and Ramesh Parajuli ${ }^{3}$ \\ ${ }^{1}$ Department of Pathology, Chitwan Medical College Teaching Hospital, Nepal \\ ${ }^{2}$ Department of Oral Medicine and Pathology, Health Sciences University of Hokkaido, Japan \\ ${ }^{3}$ Department of Department of Otorhinolaryngology, Chitwan Medical College Teaching Hospital, Nepal
}

Submission: May 09, 2017; Published: May 30, 2017

*Corresponding author: Sushna Maharjan, Department of Pathology, Chitwan Medical College Teaching Hospital (CMC-TH), P.O. Box 42, Bharatpur, Chitwan, Nepal,

Email: sushnamaharjan74@gmail.com; drrameshparajuli@gmail.com; shresthapooja@hotmail.com; neopanepuja@gmail.com

Abstract

Otolaryngologists have a common practice of requesting histopathological examination of all routine surgical specimens to analyze harbouring infections or malignancy because of fear of medicolegal issues. Thus, the aim of this study is to review the necessity of histopathological examination of tonsil or adenoid specimens, assess the risk factors of the patients and analysis of cost-benefit rate. Tonsil or adenoid specimens of 90 patients were evaluated in this study. There were 18 children and 72 adults. Three patients had adenotonsillectomy and remaining all patients had tonsillectomy only. The maximum number of patients was of 21-30 years with male-to-female ratio of 1:2. Most of the patients (56.7\%) presented with recurrent sore throat. Three patients had preoperative risk factors of unilateral enlargement of tonsil, cervical lymphadenopathy and all of them were above 50 years.

One patient had family history of exposure to Tuberculosis and ESR=55 mm/hr, later was diagnosed as tonsillar Tuberculosis on histopathological examination. Two patients had malignancy (Squamous cell carcinoma and Non Hodgkin lymphoma). We have noted low cost-benefit ratio thus, we agree with other authors regarding unnecessary of routine histopathological examination of all tonsil or adenoid specimens in absence of any preoperative risk factors.

\section{Introduction}

Tonsillar and adenoid diseases are the most common healthrelated issues in ear, nose and throat (ENT) diseases in children and adults [1]. Tonsillectomy and adenoidectomy are two different operations. However, they can be combinable if there are indications though different may coexist [2]. Chronic tonsillitis is still the commonest indication for tonsillectomy [3]; one of the definite indication is asymmetric tonsil for histopathological evaluation to rule out malignancy $[4,5]$. Adenotonsillectomy is performed in children with obstructive sleep apnea [6]. Starry mentioned in his study in 1939 that all tonsil specimens should be sent for histopathological examination [7]. However, Weibel noted in 1965 that histopathological evaluation could be omitted in children and he stated that it should be performed in older patients over 40 years of age as risk of malignancy in tonsils increases significantly after this age [8].
There is a common practice of histopathological examination of all routine surgical specimens in most institutions to analyze harbouring infections or malignancy without assessing the risk factors of the patients because of fear of medicolegal issues [9]. Review of literature has indicated that it increased the financial burden of the patients [10-21] rather than beneficial to them unless clinically significant risk factors are obvious for histopathological examination. This is especially true for developing countries like Nepal. There is a worldwide debate on the relevance of histopathological examination of tonsil or adenoid specimens. Thus, the aim of the present study is to review the necessity of histopathological examination of tonsillectomy or adenoidectomy specimens and assess the risk factors of the patients. In this study, cost-benefit rate of histopathological tests 


\section{Global Journal of Otolaryngology}

performed for all adenotonsillectomy specimens as a routine procedure was also analyzed.

\section{Methods}

A five year and three months retrospective as well as prospective study of 90 patients who underwent tonsillectomy and / or adenoidectomy, and tonsillar biopsy, those specimens which were received in the Department of Pathology of Chitwan Medical College Teaching Hospital, Bharatpur, Chitwan, Nepal were evaluated from the period of April 2011 to June 2016. The protocol had the approval of the Chitwan Medical College Institutional Review Committee (CMC-IRC). We excluded the cases without complete history and clinical findings. Eighty four patients had bilateral tonsillectomy, three patients had bilateral adenotonsillectomy, and remaining three patients had tonsillar biopsy only. Both specimens were processed and evaluated separately in the cases of bilateral tonsillectomy and adenotonsillectomy. Hence, we evaluated a total of 177 specimens. The specimens were fixed in $10 \%$ formalin, routinely processed, embedded in paraffin wax, 2-3 micron thick sections were cut, and stained with Hematoxylin and Eosin (H\&E) dye for light microscopic examinations. The results of the histopathological examinations were studied regardless of age, sex, and indication for surgery. Descriptive data was illustrated using simple statistical tables and were expressed as mean, percentages and ratios using SPSS statistics version 20.

Results

Table 1: Age distribution of patients.

\begin{tabular}{|c|c|c|}
\hline Age (Yrs) & No. of patients (n) & Percentage (\%) \\
\hline $0-10$ & 5 & 5.6 \\
\hline $11-20$ & 30 & 33.3 \\
\hline $21-30$ & 41 & 45.6 \\
\hline $31-40$ & 7 & 7.8 \\
\hline $41-50$ & 3 & 3.3 \\
\hline $51-60$ & 4 & 4.4 \\
\hline
\end{tabular}

Ninety patients were included in this study that comprised 18 children and 72 adults. Eighty four patients had bilateral tonsillectomy, three patients had bilateral adenotonsillectomy, and remaining three patients had tonsillar biopsy only from the growth. The youngest patient was 5 years, while the oldest patient was 60 years with mean of 24.23. The maximum number of patients was in the age group of 21-30 years (Table 1). There were 30 males and 60 females with a ratio of 1:2. Most of the patients $(56.7 \%)$ presented clinically with recurrent sore throat (Table 2). The commonest clinical diagnosis made was chronic/ recurrent tonsillitis (60.2\%). Malignancy was clinically suspected in two patients who had unilateral enlargement of tonsil, recurrent sore throat, cervical lymphadenopathy and history of smoking. Tonsillar biopsies were sent for histopathological examination. One other case was suspected of malignancy or Tuberculosis who presented with unilateral enlargement of tonsil, recurrent sore throat and cervical lymphadenopathy. There was family history of exposure to TB as well.
Table 2: Clinical features of the patients who had tonsillectomy or adenotonsillectomy.

\begin{tabular}{|c|c|c|}
\hline Clinical features & No. of patients (n) & Percentage (\%) \\
\hline Recurrent sore throat & 51 & 56.7 \\
\hline $\begin{array}{c}\text { Open mouth } \\
\text { breathing }\end{array}$ & 38 & 42.2 \\
\hline Oral fetor & 2 & 10.0 \\
\hline Snoring & 95 & 50.0 \\
\hline $\begin{array}{c}\text { Tonsillar } \\
\text { hypertrophy }\end{array}$ & 3 & 3.3 \\
\hline $\begin{array}{c}\text { Unilateral } \\
\text { enlargement of }\end{array}$ & 3 & 3.3 \\
\hline tonsil & & \\
\hline $\begin{array}{c}\text { Cervical } \\
\text { lymphadenopathy }\end{array}$ & & \\
\hline
\end{tabular}

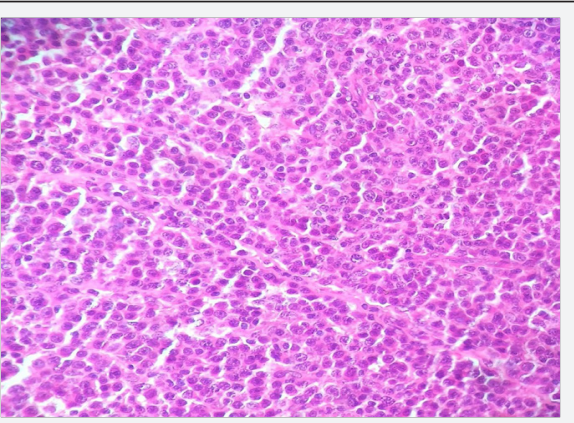

Figure 1: Histolopathological section of diffuse large cell lymphoma (Non Hodgkin lymphoma) of tonsil. (Hematoxylin and eosin stain $\times 400)$.

The $1^{\text {st }}$ case of 60 -year-old female was diagnosed as Non Hodgkin lymphoma (Figure 1). CT oropharynx revealed mass $>4$ $\mathrm{cm}$ in diameter confined to tonsillar fossa and involvement of ipsilateral level 2 and 3 neck nodes. The tumor was staged as $4 \mathrm{~A}$ with $\mathrm{T}_{3} \mathrm{~N}_{2 \mathrm{a}} \mathrm{M}_{0}$. Treatment with combined chemo-radiotherapy was given and followed up for 6 months post chemo-radiotherapy. There was and no known complication. The $2^{\text {nd }}$ case of 58-yearold male was diagnosed as Squamous cell carcinoma (Figure 2). CT oropharynx revealed tumor mass $>2 \mathrm{~cm}$ in diameter with ipsilateral level 2 and 3 neck nodes involvement. The tumor was staged as $4 \mathrm{~A}$ with $\mathrm{T}_{3} \mathrm{~N}_{2 \mathrm{a}} \mathrm{M}_{0}$. Treatment with radiotherapy was given and followed up for 6 months post radiotherapy. There was and no known complication from radiotherapy.

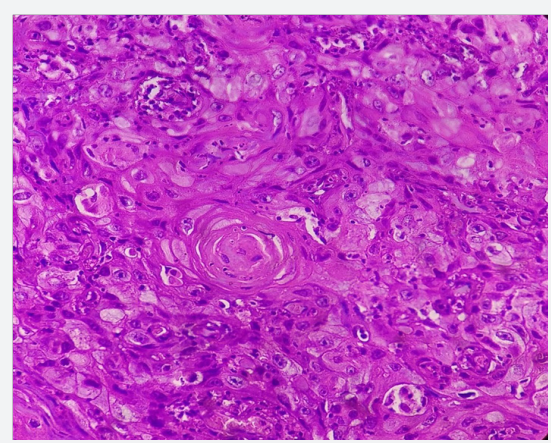

Figure 2: Histolopathological section of well differentiated Squamous cell carcinoma of tonsil. (Hematoxylin and eosin stain $\mathrm{x} 400)$. 


\section{Global Journal of Otolaryngology}

The $3^{\text {rd }}$ case of 55-year-old female had family history of TB. The differential diagnosis of TB and malignancy was made and relevant investigations were performed. ESR was $55 \mathrm{~mm}$ at 1hour. Mantoux test was positive with indurations of $20 \times 18 \mathrm{~mm}$. Tonsillar biopsy was sent and histopathological examination revealed epithelioid cell granulomas, caseous necrosis, Langhans' giant cells and lymphocytes (Figure 3). Ziehl Neelsen stain was negative for acid-fast bacilli. The case was diagnosed as tonsillar Tuberculosis. Hence, histopathological examination of tonsils was the only ultimate choice for diagnosis in these 3 cases.

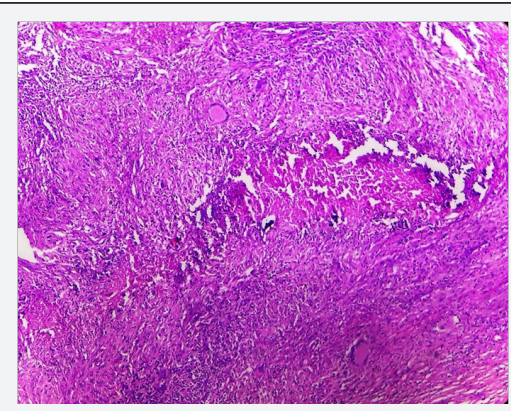

Figure 3: Histolopathological section of Tubeculosis of tonsil (Hematoxylin and eosin stain $x 40$ ).

The histopathological diagnoses are shown in Table 3. The commonest diagnosis was chronic nonspecific tonsillitis in 106 (59.8\%) specimens. Three patients who had preoperative risk factors were diagnosed as Squamous cell carcinoma, Non Hodgkin lymphoma and Tuberculosis as mentioned above. The preoperative risk factors we observed were elderly patients, history of smoking, unilateral enlargement of tonsil, cervical lymphadenopathy, family history of exposure to TB and high ESR (Table 3).

Table 3: Histopathological diagnosis of the cases.

\begin{tabular}{|c|c|c|}
\hline $\begin{array}{c}\text { Histopathological } \\
\text { diagnosis }\end{array}$ & $\begin{array}{c}\text { No. of } \\
\text { specimens (n) }\end{array}$ & Percentage (\%) \\
\hline $\begin{array}{c}\text { Chronic nonspecific } \\
\text { tonsillitis }\end{array}$ & 106 & 59.8 \\
\hline $\begin{array}{c}\text { Chronic suppurative } \\
\text { tonsillitis }\end{array}$ & 4 & 2.2 \\
\hline $\begin{array}{c}\text { Chronic tonsillitis } \\
\text { with }\end{array}$ & 6 & 3.4 \\
\hline adenoid hyperplasia & 1 & \\
\hline Tonsillar or lymphoid & 58 & \\
\hline Tuberculosis & & \\
\hline hyperplasia & & \\
\hline
\end{tabular}

\begin{tabular}{|c|c|c|}
\hline $\begin{array}{c}\text { Squamous cell } \\
\text { carcinoma }\end{array}$ & 1 & 0.6 \\
\hline $\begin{array}{c}\text { Non Hodgkins } \\
\text { Lymphoma }\end{array}$ & 1 & 0.6 \\
\hline
\end{tabular}

\section{Discussion}

There has been a debate on the necessity of histopathological examination of routine tonsillectomy or adenotonsillectomy specimens since decades. It is still controversial because the chance for a significant pathological finding in the specimens is not zero. However, criteria and guidelines relevant to the specific population are required to identify such patients who are at risk of significant pathology of the tonsils and adenoids, and decide which adenotonsillectomy specimens are needed to send for histopathological examination.

Beaty et al. [22] discussed the risk factors for tonsillar malignancy that included history of head and neck cancer, tonsillar asymmetry, visible lesion, ulceration or hard consistency on palpation of the tonsil, unexplained weight loss or constitutional symptoms and cervical lymphadenopathy. The patient initially presents with dysphasia without signs of acute infection and ipsilateral otalgia, difficulty in mobility of tongue, nasal voice, halitosis and nasal reflux. Other symptoms such as changes in tone of voice, drooling, bloody saliva and trismus indicate deep infiltration of tumor.

Mohamad et al. [12] listed the risk factors for malignancy as old age patient with history of smoking, chewing paan leaf/ betel nut, history of cancer and constitutional symptoms; associated with examination findings such as tonsil asymmetry, tonsil lesion and neck mass similar to the findings of Agoda et al. [11]. In our study we had two elderly patients with risk factors of history of smoking, tonsillar asymmetry with growth in one tonsil and cervical lymphadenopathy. Agoda et al. [11] had one adult male with risk factor of being HIV positive and diagnosed as lymphoma of tonsil on histopathological examination.

Felix at al. [9] reported $0.19 \%$ of malignancy on microscopic examination of tonsillectomy specimens in pediatric and adult patients; these patients had significant risk factors of cervical lymphadenopathy and tonsillar hypertrophy. Özbay et al. [18] had studied 2,004 patients and encountered only one malignancy with the risk factor of asymmetric tonsillar hypertrophy, cervical lymph node and weight loss. The incidence of unexplained malignancy in tonsil and adenoid specimens varies between $0 \%$ to $1 \%$ in both children and adults $[23,24]$. Özbay et al. [18] found $0.04 \%$ of unexplained malignancies which was comparable to previously published literatures such as $0.18 \%$ [25], $0.07 \%$ [21] and $0.006 \%$ [26]. Histopathological evaluation is not simply important to rule out malignancy but it is equally important for suspicious cases of TB. We encountered one case of TB who had preoperative risk factors of family history of TB, high ESR, unilateral tonsillar enlargement and cervical 
lymphadenopathy. Özbay et al. [18] also diagnosed one case of TB with preoperative risk factors including congestion of tonsils, cervical lymphadenopathy, fatigue and night sweating.

These findings suggested that if a patient has preoperative risk factors, histopathological evaluation of tonsil and adenoid specimens is mandatory and nobody should ignore it. Consequently, most surgeons no longer recommend histopathological examination for all routine cases of adenotonsillectomy specimens [10-12,14,16,18]. Many researchers found the important reason for not recommending histopathological examination of routine adenotonsillectomy specimens especially in the pediatric age group because it does not change the clinical course of management of the patients [27], and it is also not cost effective [9-11,14,16,18]. Histopathological examination of tonsillectomy/and or adenoidectomy specimens costs NRs. 1100 (USD 10) in our hospital. Our study detected malignancy in adults only and all these patients had preoperative risk factors. Pediatric patient had no abnormal or unexpected histopathological diagnosis. Thus, it suggests that histopathological examination for routine adenotonsillectomy specimens is not necessary especially in pediatric age group. We also agree with other authors regarding low cost-benefit ratio of histopathological examination of routine adenotonsillectomy specimens.

\section{Conclusion}

We conclude that in absence of any preoperative risk factors, routine histopathological examination of tonsil or adenoid specimens is not necessary. However, the common practice is still retained because clinicians fear of the possibility of legal action for missing diagnosis.

\section{Conflict of Interest}

The author declares that there is no conflict of interests regarding the publication of this paper.

\section{Acknowledgement}

We would like to thank Mr. Anil Shah, the staff of histopathology department for his technical assistance.

\section{References}

1. Guerra MM, Garcia E, Pilan RR, Rapoport PB, Campanholo CB, et al. (2008) Antibiotic use in post-adenotonsillectomy morbidity a randomized prospective study. Braz J Otorhinolaryngol 74(3): 337341.

2. DJ Blum, HB Neel (1983) Current thinking on tonsillectomy and adenoidectomy. Compr Ther 9(12): 48-56.

3. Zhang PC, Pang YT, Loh KS, Wang DY (2003) Comparison of histology between recurrent tonsillitis and tonsillar hypertrophy. Clin Otolaryngol Allied Sci 28(3): 235-239.

4. Dolev Y, Daniel SJ (2008) The presence of unilateral tonsillar enlargement in patients diagnosed with palatine tonsil lymphoma: experience at a tertiary care pediatric hospital. Int J Pediatr Otorhinolaryngol 72(1): 9-12.
5. AF Oluwasanmi, SJ Wood, DL Baldwin, F Sipaul (2006) Malignancy in asymmetrical but otherwise normal palatine tonsils. Ear, Nose Throat J 85(10): 661-664.

6. T Shintani, K Asakura, A Kataura (1998) The effect of adenotonsillectomy in children with OSA. International Journal of Pediatric Otorhinolaryngology 44(1): 51-58.

7. AC Starry (1939) XXIX Pathology of the tonsil with statistical report and microscopic study. Annals of Otology, Rhinology \& Laryngology 48(2): 346-358.

8. E Weibel (1965) Pathological findings of clinical value in tonsils and adenoids. Acta Oto-laryngologica 60(1-6): 331-338.

9. F Felix, GA Gomes, BP de Souza, GA Cardoso, S Tomita (2006) Evaluation of the utility of histopathologic examination as a routine in tonsillectomies. Revista Brasileira de Otorrinolaringologia 72(2): 252255.

10. MU Ibekwe, LO Onotai (2012) Routine histopathologic evaluation of adenoidectomy/or tonsillectomy specimens in Nigerian children: how relevant? Journal of Medicine and Medical Sciences 3(3): 179-183.

11. Adoga AS, Ma An DN, Nuhu SI (2011) Is routine histopathology of tonsil specimen necessary? Afr J Paediatr Surg 8(3): 283-285.

12. I Mohamad, S Hassan, R Salim (2007) The routine histopathological examination of tonsillectomy specimens at hospital Universiti Sains Malaysia - a retrospective study and its implication. Malays J Med Sci 14: 53-55.

13. A Adeyemo, C Okolo, S Ogunkeyede (2011) Evaluation of histopathology examination of routine tonsillectomy and adenoidectomy specimens in developing countries. Journal of Pediatric Sciences 3(3): e96.

14. G Rebechi, TE Pontes, EL Braga, WM Matos, F Rebechi, et al. (2013) Are histologic studies of adenotonsillectomy really necessary? Int Arch Otorhinolaryngol 17(4): 387-389.

15. AR Dell'Aringa, AJ Juares, CD Melo, JC Nardi, K Kobari, et al. (2001) Histological analysis of tonsillectomy and adenoidectomy specimens -January 2001 to May 2003, Revista Brasileira de Otorrinolaringologia 71(1): 18-22.

16. RT Younis, SV Hesse, VK Anand (2001) Evaluation of the utility and cost-effectiveness of obtaining histopathologic diagnosis on all routine tonsillectomy specimens. Laryngoscope 111(12): 2166-2169.

17. AC van Lierop, CAJ Prescott (2009) Is routine pathological examination required in South African children undergoing adenotonsillectomy? SAMJ: South African Medical Journal 99(11): 805-809.

18. I Özbay, M Gençoğlu, HH Balıkçı, C Kucur, F Oğhan (2013) Histopathological analysis of tonsillectomy specimens: a report from Southeastern Anatolia. Kulak burun bogaz ihtisas dergisi 24(5): 254258.

19. W Chow, BW (2015) Rotenberg, Discontinuing routine histopathological analysis after adult tonsillectomy for benign indication. Laryngoscope 125(7): 1595-1599.

20.JC Netser, RA Robinson, RJ Smith, SS Raab (1997) Value-based pathology: a cost-benefit analysis of the examination of routine and no routine tonsil and adenoid specimens. Am J Clin Pathol 108(2): 158165.

21. ME Nelson, TJ Gernon, JC Taylor, JB McHugh, MC Thorne (2011) Pathologic evaluation of routine pediatric tonsillectomy specimens: analysis of cost effectiveness. Otolaryngology-Head and Neck Surgery 144(5): 778-783.

22. MM Beaty, GF Funk, LH Karnell (1998) Risk factors for malignancy in adult tonsils. Head Neck 20(5): 399-403. 
23. A Alvi, AJ Vartanian (1998) Microscopic examination of routine tonsillectomy specimens: is it necessary? Otolaryngology-Head Neck Surg 119(4): 361-363.

24. M Ikram, MA Khan, M Ahmed, T Siddiqui, MY Mian (2000) The histopathology of routine tonsillectomy specimens: results of a study and review of literature. Ear Nose Throat J 79(11): 880-882.

25. W Garavello, M Romagnoli, L Sordo, R Spreafico, RM Gaini (2004)
Incidence of unexpected malignancies in routine tonsillectomy specimens in children. Laryngoscope 114(6): 1103-1105.

26. K Daneshbod, RA Bhutta, R Sodagar (1980) Pathology of tonsils and adenoids: a study of 15,120 cases. Ear Nose Throat J 59(11): 446.

27. MD Williams, HM Brown (2003) The adequacy of gross pathological examination of routine tonsils and adenoids in patients 21 years old and younger. Human Pathology 34(10): 1053-1057.

\section{Your next submission with Juniper Publishers will reach you the below assets}

- Quality Editorial service

- Swift Peer Review

- Reprints availability

- E-prints Service

- Manuscript Podcast for convenient understanding

- Global attainment for your research

- Manuscript accessibility in different formats

( Pdf, E-pub, Full Text, Audio)

- Unceasing customer service

Track the below URL for one-step submission https://juniperpublishers.com/online-submission.php 